\title{
A Dimensão Humana da Sustentabilidade
}

\author{
DANTAS TUMA, Lorena de Cárita ${ }^{1}$
}

1École Nationale Supérieure d'Architecture de Marseille, Marselha, França. lorenadecarita.dantastuma@marseille.archi.fr

\section{Resumo}

O progresso a qualquer custo tem negligenciado o ser humano, causando danos à saúde física, emocional e ao meio ambiente. A Arquitetura Sustentável, em busca de sanar estes prejuízos, é a nova tendência que mobiliza arquitetos, engenheiros e construtores, que atentam para o fenômeno do aquecimento global e para os benefícios econômicos trazidos pelas certificações energéticas. Porém, as práticas contemporâneas recorrem no mesmo equívoco das da segunda metade do século XIX, na cidade projetada para a máquina: esquecem a dimensão humana. Se a Arquitetura é capaz de produzir deleite, perplexidade e reverência, capaz de moldar a ordem cultural, emoldurar o bem-estar, contribuir para a saúde e felicidade, desempenha grande papel na rotina mais irrisória. As soluções de sustentabilidade, contrariamente, têm-se limitado analiticamente à adoção de novas tecnologias que por si só não conferem o bem-estar humano e, em muitos casos, nem ao menos o ar puro. É necessária uma ampla reflexão filosófica, sociológica, psicológica e holística embutida no fazer arquitetônico a fim de propiciar a sustentabilidade do planeta e a plenitude humana. Considerando, além da escassez material em que vivemos, a Arquitetura Sustentável deve mirar a miséria psicológica em que fomos imersos. Deve reconciliar o homem com a natureza, e por sua vez, a Arquitetura com a humanidade.

Palavras-chave: Arquitetura sustentável; Dimensão humana; Humanização do espaço; Sustentabilidade; Bem-estar.

\begin{abstract}
Progress at any cost has neglected the human being, causing damage to physical, emotional and environmental health. Sustainable architecture, seeking to avoid climate change, is the new trend that pushes architects, engineers and builders who pay attention to the phenomenon of global warming and the economic benefits brought by energy certificates. However, these contemporary practices rely on the same misconception as the second half of the nineteenth century, when the cities were designed for machines ignoring the human scale. If architecture is capable of producing delight, amazement and relevance; as well as being able to shape the culture, frame the welfare, and contribute to health and happiness, it plays a big role in the most ordinary of routines. However, sustainability solutions have been limited analytically to the adoption of new technologies that can't provide well-being by themselves, in many cases not even for fresh air. Sociological, psychological and holistic reflection is necessary in order to reach sustainability on the planet and full-fill human needs. The city of the future must seduce and provide delight. Focusing ahead on resource scarcity, sustainable architecture should target the psychological misery in which we are currently immersed. We must reconcile Man with nature and, in turn, Architecture and humanity.
\end{abstract}

Key-Words: Sustainable Architecture; Human dimension; Human space; Sustainability; Wellbeing. 


\section{Introdução}

As relações homem/natureza, e homem/sociedade, impulsionados pela evolução do ser humano como indivíduo e grupo, sofreram várias transformações ao longo da história da humanidade. Auxiliado no princípio por instrumentos rudimentares, o homem desprendeu energia de seu corpo a fim de assegurar a perpetuidade da sua vida e do seu grupo. Várias paisagens foram moldadas por ele no transcorrer do tempo. Manifestas pela Arquitetura, pela construção civil, documentam a história da humanidade demonstrando como foi capaz de conciliar ou desconciliar a exploração dos recursos naturais com as suas necessidades, e a estabilidade do planeta (1).

Durante longos anos, as cidades e comunidades humanas foram construídas de acordo com as questões ambientais existentes. Desta forma, muitas civilizações passaram a se desenvolver ao longo dos rios. Tal era a dependência da natureza, que as cidades se localizavam quase sempre próximas à beira de uma fonte de água potável e próximas à grandes reservatórios de água. $\mathrm{O}$ encerramento de um ciclo definia o momento de mudar o habitat. Os nômades viviam da caça e de alimentos vegetais, seguindo sazonalmente bandos de animais selvagens e colhendo os cereais que encontravam pelo caminho (1).

A partir da sedentarização - dada no Período Neolítico, iniciou-se uma mudança inter-relacional, sociedade/natureza, onde auxiliado por instrumentos complexos o ser humano efetuou, de forma aleatória, porém contínua, intervenções capazes de introduzir elementos estranhos ou de retirar elementos que asseguram o equilíbrio do ecossistema (2).

Com a evolução da sociedade em científica, moderna, industrial e tecnológica, novos métodos possibilitaram a produção de alimentos abundantes e de baixo custo. A busca pelo progresso ditada pela economia e o advento da era industrial, culminou na dualidade cidade $\mathrm{x}$ campo, compondo um eixo imaginário em torno do qual, progresso e modernização foram concebidos (3). A crença medieval de que a natureza era um bem sagrado foi substituída pela máxima que "a ciência fará da pessoa humana o senhor e possuidor da natureza" (BACON apud MARIANO et al., 2011 p. 159). O grande problema da civilização moderna, industrial e tecnológica, herdado pela sociedade contemporânea, é não compreender em como o distanciamento da natureza afeta a subjetividade humana. Lévi-Strauss, a respeito deste distanciamento da essência humana, subjugada pela velocidade do consumo, contrapôs a civilização urbana com a indígena (selvagem).

(...) Enxergo de preferência uma marca de sabedoria que os povos selvagens praticaram com espontaneidade e contra qual a rebelião moderna é verdadeira loucura, Muitas vezes eles souberam conquistar sua harmonia mental com um custo mínimo. Quantos desgastes, quantas irritações inúteis não nos pouparíamos se admitíssemos reconhecer as condições reais de nossa experiência humana, e que não depende de nós livrarmo-nos integralmente de seu ritmo? (LÉVI-STRAUSS, 2006 Pág. 129).

Surgiram inúmeras concepções urbanas no século XIX, a fim de solucionar os problemas da sociedade pós-revolução industrial. A busca pelo que hoje denominamos de sustentabilidade - imbuída na busca de bem-estar da sociedade fabril, estava subjacente no nascimento do Urbanismo como ciência, surgido no intento de compreender e sanar o rural, o industrial e o urbano, que segundo Henri Lefebvre, sucedem-se.

O conhecimento restrito às soluções tecnocráticas baseadas nas necessidades humanas que foram reduzidas na Carta de Atenas (1933), não foi capaz de solucionar os problemas da sociedade industrial, nem da sociedade moderna tardia. É visível a impossibilidade de reorientar as tecnociências sem reorganizar a subjetividade e a formação dos poderes capitalistas (4).

A Arquitetura ao longo da modernidade foi incapaz de responder às realidades humanas. $\mathrm{Na}$ era contemporânea, onde tanto o planeta quanto a estirpe que o povoa vivem ameaçadas por valores e parâmetros da economia, é necessário fazer a transição do paradigma tecnocrata para um paradigma mais progressivo, multidimensional, interdisciplinar e integral. Deve-se atentar às discussões políticas, sociais e ao bem-estar do homem, agregando o fazer arquitetônico à dimensão humana perdida na era da máquina (5). A noção de sustentabilidade e bem-estar deve ser igualmente revista. Não pode se resumir simplesmente em termos de gestão dos recursos naturais do planeta 
para assegurar a manutenção do crescimento e de produto nacional bruto (6).

A cidade, onde se concentra a maior parte da população mundial, é lugar de estresse, mal-estar, vícios e poluição (7). Sofremos com crises de abastecimento de água, mudanças climáticas, escassez de recursos e crises de valores. Tais crises, apenas se diferem em número e grau das do passado (8).

A crise ecológica advém de uma prática errônea, existencial do ser humano, que se evidenciou ao passo que sua influência no meio se tornou cada vez mais incisiva. A falibilidade de remediar as situações críticas revela que as experiências humanas passadas estão deterioradas. Não consideram a fragilidade do planeta, as novas epidemias, a gestão de resíduos e a alteração dos ciclos naturais. Tampouco estão atentas à vulnerabilidade do ser humano em um habitat "deformado", marcado por grandes catástrofes naturais (9).

A Arquitetura tem grande efeito ambiental, permeando as esferas econômica, energética e cultural, cabe à mesma uma grande mudança positiva através da integração das quatro perspectivas em si. Se a Arquitetura e o Urbanismo são capazes de emoldurar qualidades do meio ambiente, também têm o poder de restaurar o ecossistema, promover a solidariedade, a saúde mental e física, reconciliando por fim, o homem com a natureza. Porém, antes disso, há mister, atentar à dimensão humana e conciliar a Arquitetura com a humanidade (10).

\section{A perda da dimensão humana}

Uma das grandes perdas que se verificam no âmbito da Arquitetura na Modernidade é a perda da dimensão humana. A Arquitetura possui grande influência na percepção humana no que diz respeito aos seus anseios estéticos, necessidade de segurança, bem-estar. Possui dimensão socioeconômica e política, ao passo que a casa simboliza o status do proprietário, bem como o poder das instituições (11).

Para Aristóteles o homem é um animal político complexo: pertence ao mundo sublunar (terrestre), porém, integra o mundo supralunar (celeste). Distingue-se dos outros animais por ser racional, por ser um animal que possui a palavra. A voz não lhe serve apenas para exprimir alegria ou dor - como sucede nas outras espécies animais - mas, para discutir sobre o útil e o prejudicial, tal como o justo e o injusto (12). Para Aristóteles, o homem poderia ser meramente social ou meramente familiar, sem ser um animal político. E por ser animal político, não deixa de ser um animal social e familiar, onde, além da base social, há a inevitável raiz animal.

Em contraste com a complexidade humana, seus desejos e sua essencialidade política, a cultura arquitetônica foi despolitizada, distanciada das condições empíricas e objetivas e subjetivas da vida urbana (13).

O reducionismo analítico, a repetição e a generalização acrítica das soluções, a partir do paradigma mecanicista aplicados aos campos da Arquitetura e Urbanismo, produziram cidades compostas de peças e objetos arquitetônicos aleatórios, compondo um sistema de eficácia duvidosa, elevados custos de funcionamento que impulsionam os desequilíbrios e desigualdade. Múltiplas esferas são afetadas - política, econômica, social e meio ambiental (14).

Segundo Zaida Muxí (2011), se aceitamos a nova condição global como condição contemporânea, devemos estar atentos às falhas que se apresentam a partir do fim do século XX. Nesse período, surgem projetos urbanos que têm a intenção de perpetuar o indivíduo como ser independente, habitando nos subúrbios. Este conceito constitui grande insustentabilidade no meio urbano por promover altos níveis de deslocamento ocasionando o alto consumo de combustíveis. Por outro lado, acarreta uma perda significativa de parâmetros constituintes da "dimensão humana" como sociabilidade, participação política e bem-estar.

O referido modelo tardo-racionalista é marcado pela fragmentação do território e pela dispersão das áreas urbanas, conformando um mosaico de fragmentos sem relação entre si, com grande perda do espaço público em benefício de interesses individuais. Em algumas cidades, como Los Angeles, pode-se verificar a inter-relação dual homem $\mathrm{x}$ cidade substituída pela cidade $\mathrm{x}$ automóvel. O morador dos subúrbios, ou condomínios fechados - como essa realidade se manifesta no Brasil, é o resultado de uma cidade baseada no elevado consumo de energia, organizada segundo autopistas pelas quais se trafega 
em alta velocidade não permitindo ver o outro, a paisagem ou a realidade concreta. A estes fatores somam-se o medo endêmico ao desconhecido, ao contato social e à violência urbana (15).

No final do século XIX, um pensamento urbanístico tão forte quanto inconscientemente redutor, pôs de lado o habitar. Este urbanismo foi capaz, apenas, de conceber alguns atos elementares: comer, dormir, reproduzir-se. Nem ao menos pode se dizer que estas atividades seriam, animais, já que "a animalidade tem uma espontaneidade mais complexa (7).

De acordo com as interpretações de Lefebvre (2002), as cidades resultantes deste reducionismo possuem caráter paradoxal - homogêneo e desarticulado. Os espaços de ócio estão dissociados dos espaços de trabalho e de produção. Desta maneira, os espaços de lazer figuram independentes dos espaços de trabalho, mas vinculados através do consumo organizado e do poder que os reúne (16).

Em sua obra O Direito à Cidade (2008), Henri Lefebvre distinguiu conceitualmente habitar e habitat. Habitar é participar, se apropriar, usufruir de uma vida social, de uma comunidade, de uma aldeia ou cidade; é criar, é produzir mediante apropriações do espaço (e do tempo), por meio das relações. Essas relações são colocadas em primeiro plano, tendo, desta forma, o valor de uso, predomínio sobre o valor de troca. O habitat é uma imposição, instaurada por uma conjuntura externa; um atentado à diversidade de maneiras de viver; a redução do ser humano a algumas de suas funções elementares: comer, dormir, reproduzir (17).

O saber filosófico nos ensina que o homem é complexo, possuindo contradições: desejo e razão, espontaneidade e racionalidade. A análise de Lefebvre, ainda de forma mais aprofundada, elucida a importância de outros aspectos a serem considerados tais como sexos, idade, entre outros. Daí surge o grande desafio de tirar-lhe da esfera do habitat, e proporcionar-lhe o ato de habitar.

"Como criar um "habitar" que dê forma sem empobrecer uma concha que permita à juventude crescer sem prematuramente se fechar? Como oferecer uma morada ao ser humano ambíguo que só sairá da ambiguidade pela velhice, pouco formado e magnífico como tal, contraditório, mas de tal modo que nenhum dos lados da contradição pode vencer o outro sem mutilação grave $\mathrm{e}$ considerando, no entanto, que o ser deve sair da situação contraditória? ” (LEFEBVRE, 2002 p. 82).

O ser humano só pode habitar como poeta. A sua relação com a natureza e com a sua própria natureza reside no habitar. Este fato é perceptível no cotidiano mais irrisório, pois retém grandeza e poesia marcados pela espontaneidade, salvo quando é influenciado pela publicidade e encarnação do mundo da mercadoria. O habitar no pensamento urbano atual jamais foi imerso numa miséria tão profunda dentro da racionalidade, segundo Lefebvre (2002), "pretensamente urbanística”.

Os processos e condições sociais produzem uma exposição desigual a riscos dificilmente definíveis. As desigualdades resultantes devem ser em grande parte vistas como expressão e produtos das relações de poder no contexto global.

Além dos fatores que ordinariamente definem as concepções de desigualdade natural entre os seres humanos, somam-se as catástrofes naturais. Os desequilíbrios climáticos afetam as esferas urbanas e rurais, incrementando a vulnerabilidade social de populações, ao passo que estas, possuem disposição limitada para enfrentar as mudanças climáticas ou das crises econômicas globais.

A Arquitetura Sustentável, deve atingir uma aproximação holística promovendo entornos urbanos que otimizem, além dos parâmetros climáticos, a saúde mental humana e sua qualidade de vida. A saúde é determinada pelas circunstâncias do entorno, pela genética, renda, relacionamentos interpessoais, urbanização e particularidades de gênero. O racionalismo redutor e a Carta de Atenas (1933) foram responsáveis por padronizar o ser humano de forma que seu ambiente ficou aquém de sua complexidade (18).

Para um processo de retomada de valores devem ser incorporados referenciais, parâmetros e critérios mais sustentáveis. A preocupação da Arquitetura sustentável deve traspassar a esfera físico-ambiental, cujos objetivos devem ser: possibilitar a integração social; a diversidade funcional; a cidade compacta a partir de estudos de densificação saudáveis da trama urbana; fluidez de tráfico possibilitando a inter-relação de partes; investimentos em equipamentos públicos; impulso à construção de 
edificações de baixo consumo energético e a valorização dos espaços intersticiais (19).

As características topográficas e paisagísticas conferem um caráter singular aos lugares. A Arquitetura, apropriando-se delas, é capaz de conferir ao ambiente construído, um significado estético (20). A utilização do lugar através de construções que respeitam as peculiaridades do sítio resulta na conciliação do Genius Loci (espírito do lugar) com o homem.

Dessa forma, o projeto urbano sustentável, deve ser baseado nas características físicas locais, buscando satisfazer as necessidades imateriais de acordo com a cultura local - oferecendo soluções exclusivas para cada contexto, ou adaptando as soluções de realidades e semelhanças em consonância com o comportamento da sociedade onde se atua, com sistema político-econômico delimitador de fatores relevantes, como os fluxos, que por sua vez, definirão as dimensões e condições de governança, sob as quais se deve projetar o espaço urbano garantindo o seu eficaz funcionamento e governabilidade (21).

\section{Arquitetura para o bem-estar}

Existem inúmeras evidências sobre os problemas decorrentes da percepção dos diferentes símbolos e áreas urbanizadas. $\mathrm{O}$ indivíduo contemporâneo, no mundo excessivamente técnico, de Arquitetura impersonalizada por edifícios modernos, perde sua percepção do território, a dimensão estética, o senso de harmonia. O homem necessita de símbolos, trabalhos de arte significativos, capazes de representar as situações da vida. A Arquitetura consiste na visualização do Genius Loci, e o papel do arquiteto é o de criar lugares cheios de significados, impulsionando a vida e o bem-estar (10).

A "Nova Carta de Atenas", proposta por Andrea Branzi, idealiza uma cidade com todos os defeitos e contradições, que terá de sempre ser reformada, reestruturada, replanejada, na busca de equilíbrios temporários que precisam de um cenário permanente; uma cidade que corresponda a uma sociedade "autorreformadora", que todos os dias produza novas leis e regras para gerenciar, de maneira positiva, sua crise permanente (22), adotando um modelo de desenvolvimento sustentável (permanente), entendido como um conjunto complexo de estratégias que possibilitam, através do uso de instrumentos econômicos e técnicos, satisfazer as necessidades humanas, como materiais, culturais e espirituais, respeitando os limites naturais (23).

Infelizmente, na contemporaneidade, a maioria das pessoas não entendem a si mesmas, tampouco, aos outros que estão ao seu redor. Num ímpeto egocêntrico, enfatizam o individualismo, que rejeita e diverge do ambiente natural. A consequência desta conduta é a perda de identidade dos espaços construídos.

Novas condutas direcionadas à sustentabilidade devem reanimar as discussões com os potenciais políticos, sociais, culturais e críticos, que foram drenados da Arquitetura ao longo da modernidade. Com frequência os arquitetos estão coletivamente coagidos a escolher entre paradigmas urbanos excludentes, que ora priorizam a saúde ambiental, a justiça social ou a relevância cultural.

A ciência do bem-estar é uma descoberta recente. Pesquisas realizadas pelo Conselho Científico do Reino Unido, através da análise multidisciplinar de pesquisas, foram capazes de encontrar os comportamentos que mais se relacionam com o bem-estar. No relatório denominado Mental Capital Wellbeing (Bem-estar, Capital Mental), foram enumerados cinco aspectos para ação individual, direcionados ao bem-estar (24).

Relações sociais: As relações interpessoais com familiares, colegas de trabalho, vizinhos contribuem para o bem-estar pessoal e enriquecimento do cotidiano.

Atividade física: Exercícios físicos reduzem sintomas de enfermidade mental e física, além de estimular a produção dos hormônios do prazer, as endorfinas.

Observação e reflexão: Observar o seu habitat e atentar aos próprios sentimentos e pensamentos. Autoconhecer-se é fundamental para reduzir os sintomas de stress, ansiedade e depressão.

Aprendizado constante: Pessoas que valorizam o aprender, mesmo na maturidade, exercitam a memória, possuem autoestima elevada e altos níveis de bem-estar.

Fazer o bem: Indícios demonstram que atitudes prósociais e altruístas, em oposição às atitudes 
egocêntricas, estão relacionadas com o bem-estar e a felicidade.

Para dar suporte às atividades catalizadoras do bemestar, novas práticas voltadas ao espaço público devem ser incorporadas. Espaço este, figura como a materialização da democracia inscrita no tecido urbano. Sua relevância é fundamental: proporciona o senso de lugar, a identidade cultural e a fuga da rotina desenfreada (25).

O espaço público está sempre ao nosso redor. É uma parte vital da rotina urbana: as ruas que passamos no caminho da escola, os lugares onde as crianças brincam, ou onde encontramos a natureza e a vida selvagem; os parques onde praticamos esportes, caminhamos com o cachorro e sentamos na hora do almoço; ou simplesmente um lugar quieto, para aliviar os momentos de uma vida atribulada. Em outras palavras, o espaço público é nossa sala de estar ao ar livre, nosso espaço de lazer aberto (26).

Apesar da grande importância que os espaços públicos possuem, são normalmente negligenciados. Porém, não se pode prescindir de espaços verdes de qualidade quando se almeja o aumento da densidade - necessário para obtenção de uma cidade compacta e mais sustentável. Pesquisas do Japão demonstram que há maior expectativa de vida em locais com presença de áreas verdes. Lagos e árvores promovem uma queda na pressão arterial além de reduzir a sensação de estresse (10).

O ato lúdico de jogar é crucial para muitos aspectos do desenvolvimento infantil. Desenvolve habilidades sociais, experimentação, confrontação e resolução de crises emocionais. Trabalha desde o entendimento moral às suas habilidades cognitivas, como a linguagem e compressão, além das aptidões físicas.

Para as crianças e jovens o espaço público verde pode ser a garantia de um direito assegurado pelas Nações Unidas e por seus Estados integrantes, constando no decreto no 99.710 , de 21 de novembro de 1990 que promulga a Convenção sobre os Direitos da Criança na constituição brasileira:

"Os Estados-parte reconhecem o direito da criança ao descanso, ao lazer, ao divertimento e às atividades recreativas próprias da idade, bem como à livre participação na vida cultural e artística.
Os Estados-parte respeitarão e promoverão o direito da criança de participar plenamente da vida cultural e artística e encorajarão a criação de oportunidades adequadas, em condições de igualdade, para que participem da vida cultural, artística, recreativa e de lazer" (PALÁCIO DO PLANALTO).

$\mathrm{O}$ direito à cidade é ameaçado pela criminalidade. $\mathrm{O}$ medo do crime detém os indivíduos da vida pública muito mais que o próprio crime. Mulheres, crianças, jovens e idosos são impedidos de utilizar parques, praças e ruas por falhas no planejamento destes espaços e falta de gestão.

O planejamento urbano é capaz de agir diretamente nos índices de criminalidade. Estudos feitos em Los Angeles demonstram que a localização e a visibilidade das paradas de ônibus têm grande impacto na diminuição do crime. Quando as paradas são visíveis, oferecem abrigo aos usuários e estão localizadas em ruas movimentadas, a criminalidade é baixa. Porém, ocorrências de crime são elevadas se a parada de ônibus se localiza na interseção de ruas estreitas, próxima a caixas eletrônicos, edifícios vazios, estacionamento e em áreas pichadas. A experiência da cidade de Birmigham, no Reino Unido, provou que o incremento da iluminação aliado ao aumento da via de circulação para pedestres, de dois metros para três metros, foi capaz de reduzir em $70 \%$ os casos de roubo nas feiras locais (27).

A Comission for Architecture and the Built Environment - $C A B E$ (Comissão para a Arquitetura e o Espaço Construído) sediada no Reino Unido, pesquisou como a qualidade de parques e espaços públicos são capazes de influenciar o meio ambiente, a economia e a sociedade. Baseadas nas pesquisas que demonstram as atividades precursoras do bem-estar, publicou importantes aspectos que devem ser considerados por gestores e planejadores do espaço urbano. Dentre os quais se encontram:

Alta densidade e uso misto: A diminuição na dependência do automóvel afeta a autoconfiança do indivíduo. Portanto, a alta densidade e o uso misto do espaço urbano, são capazes de estimular a atividade física e o desenvolvimento de relações sociais. A cidade compacta possibilita o acesso ao transporte público, aumentando a confiança no 
próprio indivíduo, pela diminuição da dependência do automóvel.

Áreas verdes: A disponibilidade de espaços públicos, livres, abertos, para jogos, contemplação, exercícios e sociabilidade são essenciais para a realização de tarefas que proporcionam o bem-estar. Em locais de alta densidade a vegetação pode ser usada para demarcar os limites entre a propriedade pública e privada.

Circulação: Os trajetos devem ser uma experiência agradável que incentive ao movimento. Dessa forma, corredores e túneis devem ser evitados. As dimensões das faixas de circulação devem ser acessíveis aos cadeirantes e adaptadas aos portadores de mobilidade reduzida.

Espaços interiores: A orientação dos quartos e cozinha devem ser ao nascente. Dessa forma o corpo receberá estimulação solar, ideal para manter o equilíbrio do ritmo circadiano. $\mathrm{O}$ ocupante deve ter a possibilidade de controlar a entrada de luz tanto direta quanto difusa. $\mathrm{O}$ projeto deve priorizar a atenuação de ruídos, separando as zonas de estudo e descanso, dos geradores de perturbações (10).

A cor do ambiente pode ter bastante impacto no comportamento. Pesquisas concluíram que a cor vermelha e o teto baixo, aumentam a performance em atividades que requerem foco e concentração; enquanto a cor azul e o pé-direito alto, estão relacionados às atividades de criação (28).

O modo como o indivíduo atua em sociedade é uma parte da definição de saúde, em paralelo com os sintomas biológicos e psicológicos. Saúde não se refere apenas à ausência de enfermidade, não depende exclusivamente de tratamento médico. Também é determinada pela qualidade do meio ambiente, seja térmica, visual, acústica, incorporando considerações psicológicas (29).

\section{Considerações finais}

A Arquitetura necessita resgatar o seu papel fundamental nas atividades indiferentes da vida cotidiana, imbuídas no lazer, no habitar, no habitat e na utilização do espaço. A reprodução das relações sociais se realiza nas atividades mais indiferentes: na vida cotidiana, nas atividades de lazer, no habitar.
A cidade sustentável deve ser pensada e analisada em níveis e dimensões, possibilitando múltiplas leituras. A Arquitetura e Urbanismo sustentáveis são alcançados através da apreensão das lições do passado e da revisão quanto às formas de abordar a complexidade humana. Devem ser considerados os critérios biológicos, estéticos, sociais, econômicos que compõem o universo urbano. Segundo Claude Lévi-Strauss, a cidade é tão complexa como o ser que a criou. É o somatório da natureza e da técnica, resultante dos anseios da humanidade:

\begin{abstract}
"Não é, portanto, apenas de maneira metafórica que é possível comparar - como se fez muitas vezes - uma cidade a uma sinfonia ou a um poema; são objetos de natureza idêntica. A cidade, talvez mais preciosa ainda, situa-se na confluência da natureza e do artifício. Congregação de animais que encerram a sua história biológica nos seus limites, modelando-a ao mesmo tempo com todas as suas intenções de seres pensantes, a cidade provém simultaneamente da procriação biológica, da evolução orgânica e da criação estética. É ao mesmo tempo objeto de natureza e sujeito de cultura; indivíduo e grupo; vivida e sonhada; a invenção humana por excelência" (LÉVISTRAUSS, 2006 p. 130).
\end{abstract}

Ao longo do artigo, foram realizadas discussões na esfera psicológica, sociológica, econômica, histórica, as quais a Arquitetura é, indubitavelmente, capaz de permear. Na literatura, não seria distinto.

Cenário da obra de Gabriel García Márquez, a cidade de Macondo guarda grandes similaridades com as cidades em que habitamos. Originou-se do êxodo realizado por José Arcadio Buendía juntamente aos membros de sua expedição, família e amigos - este êxodo, manifestado nos dias atuais pelas migrações em escala global, é uma determinação humana ocasionada por ações humanas e dirigida à melhora da vida.

Na cidade de Macondo, havia um lugar onde a família Buendía tirava suas forças para sobreviver. Este lugar era imune ao pó e ao tempo, descrito de forma mítica por Gabriel García Márquez, como lugar santíssimo de Macondo. Nele, os familiares se preparavam solitariamente para participar da vida na comunidade e do tempo (30).

Podemos encontrar um paralelo desta realidade literária com o pensamento de Henri Lefebvre (2002), quando fala do conceito de habitar, fundamental para recobrar a consciência existencial 
humana no cotidiano. A significação dos fatos míticos da obra é relembrada na atualidade com as transformações que fizeram sofrer a fundação e a destruição da urbe, que se traduz na desolação e na solidão, decorrentes do pecado (31). Durante um largo período desta narração, ao esquecer o nome, a noção das coisas, a identidade das pessoas, e até deles mesmos, os habitantes de Macondo se tornam incapazes para construir seu porvir e manter qualquer tipo de comunicação, estando durante largo tempo submergidos na incoerência, na solidão total - problema posteriormente solucionado na ficção, por uma fórmula desenvolvida pelo sábio alquimista Melquíades (32).

Este fenômeno pode ser traduzido no contexto cidade real como a alienação dos habitantes em relação ao meio em que vivem - por este carecer de autenticidade, referenciais estéticos e de suporte às outras atividades alheias à produção.

Cabe, portanto, à Arquitetura, através de uma visão ampla, irrestrita aos índices econômicos, mas atenta à dimensão humana e à saúde física da nossa espécie, atuar com objetivo de garantir o bem-estar, a saúde e a perpetuidade das gerações futuras.

Atualmente há mister uma estrutura que permita ao homem como indivíduo e sociedade desenvolver senso de pertencimento, dar sentido à sua existência que se perfaz intrinsecamente no espaço. A cidade sustentável deve estimular a ação consciente do indivíduo, imbuída na relação com as coisas que o cercam, no ato de habitar, resultando no cuidado do espaço e no engajamento coletivo.

A sustentabilidade será, enfim, alcançada, quando deixando de exercitar meramente a alquimia ou tecnocracia, a Arquitetura se liberar do fazer restrito abrangendo as dimensões que lhes são inerentes.

Entende-se que a Arquitetura é complexa, tem caráter de arte e de extrema relevância psicossocial, já que as edificações são capazes de promover reações de cunho emocional - deleite, tristeza, perplexidade e reverência (33).

A grande cidade contemporânea, assim como a mítica cidade provinciana de Macondo, é lugar de vícios, poluições, de doenças mentais e sociais. Nela a segregação generaliza-se por bairro, profissão, idade, etnia, sexo, multidão e solidão. Nesta aglomeração caótica, quanto mais se concentra os meios de vida, mais torna-se insustentável nela viver.

\section{Referências}

1 MARIANO, Z. F. et al. A Relação HomemNatureza e os Discursos Ambientais. Revista do Departamento de Geografia - USP, São Paulo, v. 22, p. 158-170, 2011.

2 GONÇALVES SOUZA, R. Mundo Educação. Mundo Educação, 23 Abril 2015. Disponivel em: $<$ http://www.mundoeducacao.com/historiageral/re volucao-neolitica.htm>.

3 BERMUDEZ, J. Simplicidade, Ciência, Espiritualidade, Situação: Quatro maneiras de a Arquitetura enxergar o futuro. CadernosProArq, n. 22, p. 15-27, 2014.

4 CIAM - CONGRESSO INTERNACIONAL DE ARQUITETURA MODERNA. A Carta de Atenas. IPHAN, $1933 . \quad$ Disponivel em: <http://portal.iphan.gov.br/uploads/ckfinder/arquiv os/Carta\%20de\%20Atenas\%201933.pdf >. Acesso em: 2015.

5 WALDHEIM, C. Obra fraca: "a metrópole fraca" de Andrea Branzi e o potencial de projeto do "urbanismo ecológico". In: DESIGN, H. U. S. O. Urbanismo Ecológico. São Paulo: Gustavo Gilli, 2014. p. $114-120$

6 ALPHANDÉRY, P.; BITOUN, P.; DUPONT, Y. O Equívoco Ecológico. São Paulo: Brasiliense, 2000.

7 LEFEBVRE, H. A Revolução Urbana. Belo Horizonte: Editora UFMG, 2002.

8 KWINTER, S. Notas sobre a terceira ecologia. In: DESIGN, H. U. S. O. Urbanismo ecológico. São Paulo: Gustavo Gilli, 2014. p. 94-105.

9 BECK, U. Desigualdade social e mudanças climáticas. In: DESIGN, H. U. S. O. Urbanismo Ecológico. São Paulo: Gustavo Gilli, 2014. p. 106110 .

$10 \mathrm{CABE}$. Sustainable places for health and wellbeing. London: Comission for Architecture and Built Environment, 2009.

11 CANTO, R. Qual é o habitat do ser humano? Carta Capital, 2013. Disponivel em: 
<http://www.cartacapital.com.br/sustentabilidade/q ual-e-o-habitat-do-ser-humano-2944.html>. Acesso em: 23 Outubro 2015.

12 CEPP. Centro de Estudos do Pensamento Político. CEPP, 27 Outubro 2015. Disponivel em: <http://www.iscsp.ulisboa.pt/ ${ }^{\sim}$ cepp/indexfro1.php3 ?http://www.iscsp.ulisboa.pt/ cepp/conceitos_politi cos/animal_politico.htm>.

13 ŠAFRÁNKOVÁ, J. Sociological and Psychological Aspects of Architecture and Urban Space. OL PAN, p. 15-22, 2006.

14 HERNÁNDEZ, A.; MOCHKOFSKY, R. Teoría del entorno humano. Buenos Aires: Ediciones Nueva Visión, 1977.

15 MUXÍ, Z.; MONTANER, J. M. Arquitectura y Política: Ensayos para mundos alternativos. Barcelona: Gustavo Gilli, 2011.

16 URIARTE, U. M. A Rebelião do Vivido. Henri Lefebvre no Centro de Salvador. III Seminário Internacional Urbicentros. Salvador: [s.n.]. 2012.

17 LEFEBVRE, H. O direito à cidade. São Paulo: Editora Centauro, 2008.

18 JOHNSON, K. The Guardian, 11 Junho 2013. Disponivel em:

$<$ http://www.theguardian.com/sustainablebusiness/public-health-architecture-impactwellbeing >. Acesso em: 26 Outubro 2015.

19 SUÁREZ, X. L. M. Prólogo. In: GAUZINMÜLLER, D. Arquitectura ecológica: 29 ejemplos europeos. Barcelona: Gustavo Gilli, 2002. p. 8.

20 SCHULZ, N. Genius Loci. Towards a Phenomenology of Architecture. Nova York: Academy Editions, 1980.

21 GAUZIN-MÜLLER, D. Arquitectura ecológica: 29 ejemplos europeos. Barcelona: Gustavo Gilli, 2002.

22 BRANZI, A. Para um pós-ambientalismo: sete sugestões para uma "Nova Carta de Atenas". In: DESIGN, H. U. S. O. Urbanismo Ecológico. São Paulo: Gustavo Gilli, 2014. p. 110-113.

23 SPIRN, A. W. The Granite Garden. Estados Unidos: Basic Books, 1984.
24 THE GOVERNMENT OFFICE FOR SCIENCE. Foresight Mental Capital and Wellbeing Project. London: [s.n.], 2008. Disponivel em: <https:/www.gov.uk/government/uploads/system/ uploads/attachment_data/file/292450/mentalcapital-wellbeing-report.pdf>. Acesso em: 2015 Outubro 26.

25 ŠAFRÁNKOVÁ, J. Urban Revitalization And Possibilities Of Public Participation. OL PAN, p. 95 103, 2005.

26 CABE. The Value of Public Space. London: CABE $2004 . \quad$ Disponivel em <http://www.designcouncil.org.uk/sites/default/file s/asset/document/the-value-of-public-space1.pdf $>$. Acesso em: 26 Outubro 2015.

27 ŠLHÁNKOVÁ, V. Indicators of Sustainable Development for Municipalities. Prague: Civitas per Populi, 2011.

28 MEHTA, R.; ZHU, R. Blue or Red? Exploring the Effect of Color on Cognitive Task Performances. SCIENCE, 27 Fevereiro 2009. 1226-1229.

29 STEEMERS, K. Architecture for well-being and health. D\&A Magazine, p. 1-22, 2015. Disponivel em

$<$ http://da.velux.com/arLB/Documents/PDFs/DA23_articles/DA23_Archite cture-for-well-being.pdf $>$. Acesso em: 26 Outubro 2015.

30 GALLO, M. El tiempo en "Cien Años de Soledad" de Gabriel García Marquez. Actas IV. [S.l.]: [s.n.]. 1971. p. 561-571.

31 KULIN, K. Mito y realidad en "Cien años de soledad". AIH. [S.1.]: [s.n.]. 1971. p. 91-100.

32 MARQUEZ, G. G. Cien Años de Soledad Argentina: Debolsillo, 2008.

33 GOLDBERGER, P. A Relevância da Arquitetura. São Paulo: BEÎ Comunicação, 2011

34 LEVI-STRAUSS, C. Tristes Trópicos. São Paulo: Companhia das Letras, 1996.

35 PALÁCIO DO PLANTALTO. Decreto no 99.710 de 21 de novembro de 1990. Disponivel em: <http://www.planalto.gov.br/ccivil_03/decreto/199 0-1994/D99710.htm>. Acesso em: 26 Outubro 2015. 